\title{
FIRST EFFORT ANGINA SECOND WIND IN ANGINA PECTORIS
}

BY

\section{R. KEMBALL PRICE}

From the Cardiac Department, Royal Sussex County Hospital, Brighton

Received June 30, 1950

The ability of certain patients subject to angina pectoris at the beginning of a particular effort thereafter to undertake further and even greater exertion without pain has been recognized since Heberden's time, and was compared by Wenckebach with the "second wind" of athletes. My attention was first directed to this phenomenon by three striking examples, in which strenuous athletic activity, squash racquets, ice hockey, and fencing, could be carried on after initial difficulty due to angina pectoris. With interest thus aroused it was found that the condition is by no means uncommon.

A search yielded many brief references and three more detailed contributions-Gallavardin, 1925, Wenckebach, 1928, and Wayne and Graybiel, 1934. The earliest found was the letter to Heberden from an unknown gentleman (Heberden, 1785) who wrote: "I have frequently, when in company, borne the pain, and continued my pace without indulging it; at which times it has lasted for five to perhaps ten minutes, and then gone off, as well as I can recollect, rather suddenly, as it came on, than lessening gradually." It is mentioned by Trousseau (1881), and Osler (1897) quotes one patient who assured him that in moderate attacks on the street, by a strong effort of will he could continue to walk and the pain gradually subsided. Verdon (1910) reported: "After several breaks in the journey, and when gastric distension had been relieved by repeated eructations of flatus, a considerable length of road might be transversed without the occurrence of any further manifestations of thoracic discomfort." Allbutt (1915) quotes a case of Parry's, but states that in his own experience stillness had been invariable. Mackenzie (1916) considered the phenomenon remarkable and regarded it as evidence that " in these hearts a good deal of healthy muscle is present and that the attacks of distress are provoked by the introduction into the picture of some factor which is not myocardial weakness-for example, a full stomach."

Gallavardin (1924 and 1925) described the condition briefly and introduced the term " mise en train difficile." In his monograph (1925) he described it more fully, stating: "Many subjects say that their attacks come much more easily, sometimes almost exclusively at the beginning of their outings; they stop several times for example in the first 500 to 600 metres, then later, ' when they have warmed up,' they say walking becomes easier." He contrasts it with dyspnœa of effort which shows no such vagaries. He suggested that subjects of angina have a mechanism which is slow to adapt itself, as if things were a little stiff or rusty, and that exercise loosens them up. He felt that this fitted in well with coronary spasm. He cites another of his patients who experienced a severe attack of angina while hunting: not wishing to give in, he had, at the price of severe pain, continued and was very surprised to feel the pain go suddenly; this was followed by profuse sweating. Gallavardin remarks that such sweating, which he had noted in another patient, is never seen with attacks of dyspnœa occurring on effort, and that such a sudden termination favours the cessation of a spasm. A final point in favour of angiospasm is the marvellous efficacy of the vasodilators, notably nitrites, in the relief of attacks.

Wenckebach (1928) wrote an article with the title "Toter Punkt, Second Wind, und Angina 
Pectoris." For the translation of " toter Punkt" I am indebted to Dr. Parkes Weber who renders it "dead point," but thinks there is no exact English equivalent. This is the moment when the untrained runner feels like dying, before the relief of the "second wind" comes. Wenckebach describes the strange oppression noticed at the onset of a major physical effort. This "initial inhibition" is only of very short duration. If the activity is continued, sometimes consciously or unconsciously at a more leisurely rate, this oppression disappears; this relief, after the " first wind " seemed to have spent itself, is called "second wind." The initial inhibition may be so strong that the effort must be discontinued; the "toter Punkt" (dead point) is reached, and can only be overcome by a short rest or forced effort. He believed the physiological mechanism to be as follows. The beginning of exertion brings about an increased blood flow to the heart which originates chiefly in the venous splanchnic bed, but most important is that apparently the blood flow from the central arteries to the periphery and into the veins is at first still blocked-a mechanism that causes even under physiological conditions a phase of arterial mainly aortal engorgement. He states that nitrites will interrupt this initial phase and so forestall the development of "toter Punkt." He goes on to say that an attack of angina shows a complete analogy with these features. Following Allbutt's hypothesis he believed the pain to be due to distension of the aorta and larger arteries by raised blood pressure due to peripheral vaso-constriction. The pain in turn further raised the blood pressure causing a vicious circle.

Sutton and Lueth (1930) suggested " that the anatomically normal heart may, under conditions of extreme exertion, fail to receive sufficient blood (nutrition) through normal coronary arteries. In fact, this is suggested in the sensation of athletes just before " getting their second wind." They remark upon the surprising similarity between the sensations of an extreme effort in youth and of angina pectoris in later life, and quote "the unsolicited observation of a patient that the sensation felt as a young man after running up a mountain side during an emergency, was exactly the same as that now felt thirty years later during an attack of angina pectoris."

Lewis (1932) advanced the view that the pain in muscular ischæmia is due to a substance that develops in the tissue spaces around the muscle fibres and accumulates when there is oxygen lack. He quotes the letter to Heberden and adds: "That is a phenomenon difficult to explain by a simple basis of pressure and rates, but is easy to understand if it is believed that the coronary circulation accommodates itself gradually to the condition of exercise." He considered coronary constriction the most important factor.

Wayne and Graybiel (1934) in an important paper reported the results of investigation into the effect upon exercise tolerance of food, distension of the stomach, external temperature, and repeated exercise in patients suffering from angina pectoris. They used a two-step exercise and counted the number of efforts required to produce pain under various conditions. Two of their cases showed increased tolerance on repeated exercise. In one of these the initial number of efforts was 58; fifteen minutes later 116 efforts were performed before pain occurred. They found a diminution of tolerance if a second attempt was made within two minutes of the first, and in most cases exercise tolerance was unaltered when fifteen minutes rest was given.

Brief references are made by Cowan and Ritchie (1935), Levy (1936), and Levine (1945). Bramwell and King (1942) mentioned the term " second wind " and suggested that coronary dilatation might play a part in this adaptation which was considered to be a favourable omen in prognosis.

Patterson, Clark, and Levy (1942) observed cardiographic changes suggestive of a similar adaptation during the "anoxæmia test" in certain patients with coronary sclerosis. "In many of the cases of coronary sclerosis the total RS-T deviation increased in linear fashion as the test progressed. In some, the degree of deviation rose to a peak and then decreased. The latter sequence of events suggested that compensatory mechanisms in the circulation had brought about a favourable adjustment in coronary flow. One of the methods of adaptation appeared to be an increase in pulmonary ventilation." Bedford (1943) quotes the case of a doctor with angina pectoris who, in order to work in comfort, deliberately provoked his pain by cranking up his car so as to get it over before starting his morning round. 


\section{The Present Series}

This consists of twenty patients who showed this phenomenon. All were believed to be suffering from coronary sclerosis. A supplementary case showed a similar condition during paroxysmal tachycardia.

Incidence. There has been considerable difference of opinion as to the frequency with which " second wind" occurs in patients subject to angina pectoris. Allbutt (1915) had never seen a case personally. Cowan and Ritchie (1935) and Lewis (1933) considered it rare. Gallavardin (1925) regarded the phenomenon as common but a forced stop as more usual; he said that if asked many patients described it. Wenckebach (1924) stated that it was " by no means uncommon," and Mackenzie (1916) referred to "many people" who have difficulty in starting from rest. Wayne and Graybiel (1934) as a result of their experiments concluded that in angina of effort there is usually a phase of increased exercise tolerance, but, as this is often short, it is difficult to demonstrate clearly.

The condition is certainly noted more often when the possibility is kept in mind during the interrogation. Not all patients who have experienced " second wind "will volunteer the information in a routine history, and without a specific question on this point cases will frequently be overlooked. If deliberate enquiry is made from all patients with cardiac pain a positive answer may be obtained as often as once in every five cases.

Age, Sex, and Occupation. The youngest was 33, and the oldest 73 years old. Fifteen were between 50 and 70. All were men. This does not differ significantly from the expected findings for angina pectoris. Occupation was varied and in no way remarkable.

Effect of Tobacco. Of 13 patients questioned about this, 4 were non-smokers, 8 smoked moderately, and 1 heavily.

Hypertension. Taking $165 / 100 \mathrm{~mm}$. $\mathrm{Hg}$ as the upper limits of normal, a third of the patients in the series was hypertensive. Though previous hypertension may have been reduced in some by cardiac infarction, all except three of those with normal blood pressures had normal-sized hearts on radioscopy. Of the three exceptions two had suffered posterior cardiac infarction and the other had aortic incompetence.

Need for Rest Pause. Some patients stop once, twice or more soon after setting out, others carry on without stopping. The strong effort of will required by the latter has been mentioned by Osler (1897), Parry quoted by Allbutt (1915), Gallavardin (1925) and Wenckebach (1928). The difference appears to be in the patient's character. Those of a strong and determined nature will endure more pain temporarily in order to walk it off. Others are content to pause a few times until adaptation has occurred and they can move freely without pain.

Time of Day. Some patients are conscious of difficult starting only in the morning and not later in the day. Mackenzie (1923) pointed out that " during sleep the output of the heart is at its minimum, and the heart muscle requires like the other organs a minimum supply of blood. He suggested that this might be due to some of the capillaries having closed down during rest. Gallavardin (1924) thought " mise en train difficile" tended to occur more in those whose pain was worst first thing in the morning. Bedford (1943) mentions the "first walk of the day " and Levine (1945) cites those who " may have a spell going to the train after breakfast and be free for the rest of the day."

One patient volunteered: “After the first hole I don't get it again." Another stated: “ On going out to golf after breakfast at 9 a.m. on the first two holes I felt pain at mid-sternum, and then it went off after playing the third and subsequent holes. It vanished." The occurrence of pain during the first hole or two of a round of golf has been frequently observed (Levy, 1936; Levine, 1945; and six cases in this series).

The Part Played by the Stomach. It has been suggested that in " second wind" the gastric factor may be of greater importance than it is in ordinary angina of effort. Mackenzie (1916) thought that " the attacks of distress are provoked by the introduction into the picture of some factor 
which is not myocardial weakness-for example, a full stomach." Relief from belching was mentioned by Verdon (1910) and was mentioned voluntarily by four of this series. In those who notice the pain particularly when starting after breakfast (three cases), both first effort of the day and a full stomach may have played a part. Wayne and Gabriel (1934) found that exercise tolerance in patients suffering from angina pectoris of effort was diminished after food but not after distending the stomach with air. One of their cases with spontaneous pain also got it on distension with air. This was thought to be due to vasomotor changes reflexly from gastric distension.

Gilbert et al. (1940) produced some experimental evidence that in dogs distension of the stomach reduces coronary flow, but Wiggers (1944) commenting on this work considered that the conclusions "cannot be accepted as indisputable." Of the subjective relief in certain cases after belching there can be no doubt.

Effect of Nitroglycerine. Wayne and Graybiel (1934) found that nitro-glycerine increases exercise tolerance considerably in all cases showing this phase of increased tolerance, and concluded that a previous attack of angina acts similarly to nitroglycerine although in each case a greater effect is produced by the drug. In two cases showing no raised exercise tolerance they suggested that the coronary circulation remained unaltered during exercise, for the exercise tolerance of one was unaffected and the other only slightly increased by nitroglycerine in full doses.

In this series it was found that the difficult start could sometimes be prevented by a prophylactic dose of nitroglycerine (three cases).

\section{Prognosis}

The prognosis in patients showing "first effort angina" has been thought by some to be particularly favourable (Mackenzie, 1916; Bramwell and King, 1942).

Consideration of the present series does not support this view. In only one could the electrocardiogram be passed as normal. One showed slight widening of QRS complexes and a QIII. Five showed $\mathrm{R}-\mathrm{T}$ deviations. Six had abnormal $\mathrm{T}$ wave inversion. In seven there was a clinical history suggestive of coronary thrombosis, and in one of these "first effort pain " started a fortnight before an extensive anterior infarction from which the patient died a fortnight later.

In some it appeared as an early symptom-pain only when playing the first hole or two of golf would after weeks or months give place to pain all round (three cases). The most striking example was a patient who played in ice hockey matches without pain after the first five minutes, and he had never had pain at rest. His electrocardiogram, however, showed $\mathrm{T}$ wave inversion in all the unipolar præcordial leads which took months to recover. "First effort pain " sometimes followed cardiac infarction (three cases) or was followed by cardiac infarction (five cases). It may be that the cardiologist tends to see the more severe cases of angina pectoris, and it is possible that many patients with pain confined to first effort may not seek medical advice, or even if they do so may not be referred to a consultant. There is no proof of this, however, and I have found no evidence that the prognosis of "first effort angina" is any different from that of angina of effort generally.

\section{MeChaNisM}

It would probably be agreed now that "second wind" in angina pectoris is due to some form of adaptation of the coronary circulation to exercise. It is in attempting to determine more exactly the mechanism involved that difficulties are encountered. Lovatt Evans (1949) writes, "Despite its importance, we are still in doubt regarding many aspects of the coronary circulation as it operates in the normal heart in the intact chest, since nearly all available methods of experiment introduce some abnormal factor of incalculable effect."

Coronary spasm was suggested by Gallavardin (1925). Parkinson and Bedford (1931) from their observations on the electrocardiogram during brief attacks of angina pectoris, took the view that coronary spasm does in fact occur in angina pectoris, and suggested that narrowing of a main coronary branch might predispose to spasm of the arterioles that spring from it. The 
rapid reversal of $\mathrm{T}$ wave inversion by nitroglycerine sometimes seen in spontaneous angina (Kemball Price and Janes, 1943). and the cardiographic changes that come and go during smoking (Wilson and Johnston, 1941) provide further evidence of the existence of coronary spasm. Lewis (1932) believed coronary constriction to be the most important factor in difficult starting.

Failure of the coronary arteries to dilate rather than spasm was suggested by Sutton and Lueth (1930). Greene (1931) demonstrated that in the dog the coronary constrictor reactions are very small compared with the coronary dilator reactions, and he suggested that "during coronary sclerosis, and during the period of loss of coronary resilience preceding massive sclerosis, the arteries are less constricted by reflex constrictor nerve impulses, in fact cannot be thrown into spasm because of the rigidity and non-resilience. On the other hand, neither can such vessels respond to reflex coronary dilator reactions, hence they do not, in fact cannot, increase the blood supply under the very conditions that greatly augment the work of the heart.

Coronary dilatation as the cause of " second wind" as suggested by Wayne and Graybiel (1934) and Bramwell and King (1942) is not incompatible with a preceding coronary spasm. It is also consistent with a failure to dilate if the rigidity is in the larger arteries and the dilatation is confined to the arterioles. That a similar phase of increased exercise tolerance occurs in some patients with intermittent claudication has been stated by Ratcliffe (1949) and was observed in one case in this series. According to Allen, Barker, and Hines (1947) the arterioles in extremities afflicted by arteriosclerosis obliterans are in a condition of normal tone most of the time, thus they are susceptible to either vaso-dilatation or vaso-constriction.

It would appear that in patients with "first effort angina" there is some delay in coronary dilatation at the beginning of exercise. The important influence of mean aortic pressure on coronary flow is well established (Wiggers and Cotton 1933). Wiggers (1923) had already shown that the height of the blood pressure, as a rule, overbalances active vasomotor changes. Thus, if a general vasoconstriction, in which the coronary vessels partake (for example after adrenalin) is induced, and the blood pressure is raised in this way, the flow through the heart will increase. It is conceivable that narrowing of the larger coronary arteries from atheroma might not only predispose to spasm of the arterioles, but might prevent sufficient head of pressure being developed to overcome their spasm or constriction. "Second wind" might occur when the arterioles dilate independently.

\section{SUMMARY}

First effort angina may be defined as that which develops soon after a particular effort begins, but disappears despite continuation of that effort. A brief pause or curtailment on account of the pain is usual but not invariable, and thereafter the particular effort may be completed or even extended without further discomfort. This form of angina pectoris has been compared in respect of pain with " second wind" in respect of dyspnca. A series of 20 patients who showed the phenomenon was collected and analysed, and the subject is discussed.

First effort angina is fairly common. Few patients with angina describe it voluntarily, but if questioned one out of five may admit that they have experienced this modification of it.

No evidence has been found to suggest that the prognosis differs from that of angina pectoris generally. In course of time it gives place to the usual form which compels relinquishment of the effort.

It is possible in a proportion of cases to prevent the first effort pain by nitroglycerine taken before starting.

It seems likely that the difficult start is due to failure of the coronary arterioles to dilate soon enough on first effort. Narrowing of a large coronary vessel from arterial disease might predispose to transient spasm of the arterioles it serves, and might also tend to reduce the influence of the rise of aortic pressure at the beginning of exercise on coronary flow.

I wish to thank Sir John Parkinson for much help and encouragement in the preparation of this paper and for allowing me to use his notes of six cases. Dr. Mestitz kindly translated Wenckebach's article for me. 


\section{REFERENCES}

Allen, E. V., Barker, N. W., and Hines, E. A. (1947). Peripheral Vascular Diseases. Philadelphia, p. 363. Allbutt, T. C. (1915). Diseases of the Arteries including Angina Pectoris. Vol. II: London, p. 328. Bedford, D. E. (1943). Brit. Encycl. Med. Pract. (Rolleston, 1936), 4th Imp., 1943. Vol. I., p. 554. Bramwell, C., and King, J. T. (1942). The Principles and Practice of Cardiology. London, p. 180. Cowan, J., and Ritchie, W. T. (1935). Diseases of the Heart. 3rd ed. London, p. 420.

Evans, C. L. (1949). Principles of Human Physiology. 10th ed. London, p. 601.

Gallavardin, L. (1924). J. Med. Lyon., 113, 537. (1925). Les Angines de Poitrine. Paris, p. 119.

Gilbert, N. C. et al. (1940). Amer. Heart J., $20,519$.

Greene, C. W. (1931). J. Missouri State med. Assn., 28, 466.

Heberden, W., letter to (1785). Med. Trans. College of Physicians. 1st ed., III, 3.

Levine, S. A. (1945). Clinical Heart Disease. 3rd ed. Philadelphia, 85.

Levy, R. L. (1936). Diseases of the Coronary Arteries and Cardiac Pain. New York, p. 207.

Lewis, T. (1932). Arch. intern. Med., 49, 713. (1933). Diseases of the Heart. London, p. 51.

Mackenzie, J. (1916). Principles of Diagnosis and Treatment in Heart Affections. London, p. 75. (1923). Angina Pectoris. London, p. 38.

Osler, W. (1897). Lectures on Angina Pectoris and Allied States. Edinburgh, p. 52.

Parkinson, J., and Bedford, D. E. (1931). Lancet, 1, 15.

Patterson, J. E., Clark, T. W., and Levy, R. L. (1942). Amer. Heart J., 23, 837.

Price, R. K., and Janes, L. R. (1943). Brit. Heart J., 5, 134.

Ratcliffe, A. H. (1949). Lancet, $2,1128$.

Sutton, D. C., and Lueth, H. C. (1930). Arch. intern. Med., 45, 827.

Trousseau, A. (1881). Lectures on Clinical Medicine. Translated by P. V. Bazire. New Sydenham Society. London, p. 609.

Verdon, H. W. (1910). Heart, 1, 230.

Wayne, E. J., and Graybiel, A. (1934). Clin. Sci., 1, 287.

Wenckebach, K. F. (1924). Brit. med. J., 1, 809. (1928). Wien. klin. Wschr. 41, 1.

Wiggers, C. J. (1923). Circulation in Health and Disease. 2nd ed. New York, p. 156. (1944). Physiology in Health and Disease. 4th ed. p. 724. , and Cotton, F. S. (1933). Amer. J. Physiol., 106, 9.

Wilson, F. N., and Johnston, F. D. (1941). Amer. Heart J., 22, 64. 